\title{
Improving Health Care Globally: A Critical Review of the Necessity of Family Medicine Research and Recommendations to Build Research Capacity
}

\author{
Chris van Weel, $M D, P b D, F R C G P^{1}$ \\ Walter W. Rosser, MD, CCFP, FCFP, \\ $M R C G P(U K)^{2}$ \\ ' Department of Family Medicine, University \\ Medical Centre Nijmegen, Nijmegen, The \\ Netherlands \\ ${ }^{2}$ Department of Family Medicine, Queens \\ University, Kingston, Ontario, Canada
}

\begin{abstract}
An invitational conference led by the World Organization of Family Doctors (Wonca) involving selected delegates from 34 countries was held in Kingston, Ontario, Canada, March 8 to 12, 2003. The conference theme was "Improving Health Globally: The Necessity of Family Medicine Research." Guiding conference discussions was the value that to improve health care worldwide, strong, evidencebased primary care is indispensable. Eight papers reviewed before the meeting formed the basic material from which the conference developed 9 recommendations. Wonca, as an international body of family medicine, was regarded as particularly suited to pursue these conference recommendations:
\end{abstract}

1. Research achievements in family medicine should be displayed to policy makers, health (insurance) authorities, and academic leaders in a systematic way.

2. In all countries, sentinel practice systems should be developed to provide surveillance reports on illness and diseases that have the greatest impact on the population's health and wellness in the community.

3. A clearinghouse should be organized to provide a central repository of knowledge about family medicine research expertise, training, and mentoring.

4. National research institutes and university departments of family medicine with a research mission should be developed.

5. Practice-based research networks should be developed around the world.

6. Family medicine research journals, conferences, and Web sites should be strengthened to disseminate research findings internationally, and their use coordinated. Improved representation of family medicine research journals in databases, such as Index Medicus, should be pursued.

7. Funding of international collaborative research in family medicine should be facilitated.

8. International ethical guidelines, with an international ethical review process, should be developed in particular for participatory (action) research, where researchers work in partnership with communities.

9. When implementing these recommendations, the specific needs and implications for developing countries should be addressed.

The Wonca executive committee has reviewed these recommendations and the supporting rationale for each. They plan to follow the recommendations, but to do so will require the support and cooperation of many individuals, organizations, and national governments around the world.

Ann Fam Med 2004;2(Suppl 2):S5-S16. DOI: 10.1370/afm.194.

\section{INTRODUCTION}

7 he aim of medicine everywhere is to provide safe, effective, efficient, timely, patient-centered, and equitable care. ${ }^{1}$ To pursue this aim, strengthening primary care-the point of first contact with the 
health care system for most people-is important. Most people receive formal medical care in primary care, ${ }^{2,3}$ and it is in that setting most episodes of illness are treated. Family medicine is a key discipline of primary care, and in many countries family physicians are the only physicians directly accessible to the public. ${ }^{4}$ Clinical decisions made on first encounters often determine whether health care resources are appropriately used. ${ }^{2,5-7}$ Strengthening the knowledge base in primary care will contribute to better medical care for all.

Against this background an invitational conference was organized by the World Organization of Family Doctors (Wonca) to explore ways to improve the status of family medicine research, expand the evidence base of family physicians, and contribute to better health care worldwide. This article summarizes the conference discussions and presents recommendations proposed by the 74 conference attendees from 34 countries.

Although key components of primary care, family medicine and primary care are not identical concepts. Family physicians in different countries work with other primary care professionals in a variety of arrangements. Because of the international divergence in primary care structure, we wish to clarify that the target discipline of this paper is family medicine. Throughout the document family medicine and family physician (FP) are used and should be interpreted as the European, Australian, and New Zealand "general practice" and "general practitioner."

\section{METHODS: THE CONFERENCE PROCESSES}

The international conference organized by Wonca, in Kingston, Ontario, Canada, from March 8 to 11, 2003, provided the material for this article. Participants were leaders in primary care research in their countries. The meeting was initiated, organized, and chaired by the authors. Before the meeting every participant was asked to read 8 papers that had been written and peer reviewed by 4 reviewers especially for the conference. ${ }^{8-15}$ Each paper addressed different aspects of family medicine research. After the opening keynote address, ${ }^{16}$ the author of each paper had 10 minutes to comment on suggestions provided through the peer-review process. These comments were followed by a further 10 minutes of comments about the paper made by an individual from outside family medicine research. ${ }^{17}$ Papers were modified after the meeting on the basis of the peer review and feedback from conference participants and the guest editor for this supplement.

Conference participants then convened into 8 small groups for an extended discussion of the issues raised by each paper. Each group included representatives from both developed and developing countries, as well as those from outside the family medicine research arena. Feedback from the small groups was provided to the assembled conference. This feedback highlighted the most important points in each paper, identified gaps in content, and provided 1 or 2 recommendations. From this process several issues were identified for more discussion. The program plan allowed time for additional discussions by small groups, with reports back to the full assembly. Designated reporters for each group recorded all small-group proceedings.

The oral and written proceedings from 48 smallgroup sessions and the large-group discussions were reviewed and consolidated by the authors into this article. The findings are grouped in relation to the main conclusions and recommendations formulated during the conference. Vignettes provided in the text were developed from 2 sources. Some were chosen from two 1-hour sessions in which participants from 11 countries had 10 minutes to present a unique development. The other source was ideas emerging from group discussions during the conference. Vignettes were chosen for their ability to serve as models that are transferable to other settings.

During the large-group sessions all recommendations were reviewed and consolidated into the final 9 that were viewed by the assembly as best contributing to further development of family medicine research internationally. The need for concerted actions on these recommendations was stressed, and the conference identified the key role of Wonca in implementation. For clarity in this article, the recommendations have been formulated as generic statements. Draft versions of this report were sent to conference participants for their comments on two occasions, and all comments received have been considered for incorporation into the paper.

\section{RESULTS}

\section{Research in Family Medicine Improves Patient Care and Health}

FPs provide their services in direct contact with the communities where patients live and work: the ecology of health care $^{3}$ (see Green, Figure $1^{9(\mathrm{p} 24)}$ ). FPs work at the interface between community and the health care system. They treat most health problems in their own clinical setting, and coordinate with other sectors of the health care system for the management of an important minority of health problems. Family medicine research helps sustain the proper functioning of health care systems and guarantees access to health care on the basis of individuals' needs in a framework of equity of access for all persons. Substantial research from family medicine supports these statements, ${ }_{1}^{6,18}$ but health care funders, planners, publishers, and others often have poor under- 


\section{Vignette 1. Clinical Uncertainty}

Clinical uncertainty is an inherent aspect of first-contact medical care and should be distinguished from insecurity of individual practitioners. FPs have developed the methods to deal with clinical uncertainty that are based on the scientific concept of increasing the pretest likelihood of a disease. By watchful waiting, 40\% of undifferentiated problems encountered by FPs will resolve without ever meeting the criteria of a specific diagnosis. The remaining $60 \%$ of problems will develop signs and symptoms that will increase the pretest likelihood of a specific diagnosis. The strategy of watchful waiting, which is unacceptable in most secondary and tertiary care practice, saves unknown but large expenditures in health care investigations that would otherwise be wasted. ${ }^{18,21}$

standing of the current contribution of family medicine research and of its potential to improve health. To improve the profile and understanding of family medicine research in the medical research community, family medicine research must be more widely disseminated.

\section{Recommendation 1}

Wonca should develop a strategy to display research achievements in family medicine to policy makers, health funders, and academic leaders.

\section{Problem Solving in Family Medicine}

In family medicine problem solving has often been characterized as coping with the clinical uncertainty arising from the breadth of the clinical field. ${ }^{3}$ Forty percent of all new undifferentiated health problems never evolve into a condition that meets the criteria for a diagnosis according to the International Classification of Primary Care (ICPC) ${ }^{19}$ or the International Classification of Diseases (ICD-10); yet, in the remaining $60 \%$ of these problems, there is the possibility of every disease known to man. ${ }^{18,20}$ The way clinical uncertainty implicit in the early signs and symptoms of disease is managed determines the efficiency and effectiveness of patient care and the appropriate use of primary and secondary care diagnostic and therapeutic facilities (Vignette 1). The more common the health condition, however, the less it is studied, ${ }^{22}$ and available studies from selected populations and tertiary care centers are difficult to translate to family medicine. ${ }^{23}$ For these reasons only, rigorous research of common health problems in the community, derived from the clinical context of family medicine, will appropriately support FPs in their management of clinical uncertainty ${ }^{20,24}$ and increase the precision of their problem solving. Family medicine research will promote understanding of the origins and natural history of disease and will identify factors that enable health, as well as determinants of seeking and receiving health care.

Research to improve FP problem solving must include the broader context of patient care, ${ }_{1}^{25}$ the biopsychosocial reality of patients and their families with their values and expectations, and the socioeconomic and cultural determinants of health. Including the patients' context requires a mixture of methods and approaches in family medicine research. The application of different paradigms is also an expression of the complexity of family medicine research.

\section{Transfer and Implementation}

The transfer and implementation of new knowledge and skills gained from research in family medicine are essential to achieve the full potential of benefits to be gained for health in any community. There is a need to assess and value new knowledge in relation to the study population from which it was derived, and to determine whether the results can be generalized to other patient populations. It is important to appraise critically the potential risks and benefits of any innovation for patients in each family medicine setting. ${ }^{21}$ The concepts of evidence-based medicine provide one framework to assess the value of new innovations for each community ${ }^{21,26-28}$ (Vignette 2). There is a further need to better understand current practices and to analyze how to transfer best practices effectively to change the delivery of health care in the community, while considering each patient's personal context. Participation in practice-

\section{Vignette 2. Research and Clinical Decision Making in Family Practice}

Finding out where research fails in its support for clinical decision making is challenging for researchers. The Dutch College of General Practitioners has developed evidence-based guidelines for family physicians for the most common health problems in primary care. Seventy-six practice guidelines are published in Dutch, 7 in English ${ }^{27}$ (Web site: http: //nhg.artsennet.nl?s=4512). These guidelines summarize available evidence; at the same time, they single out where no research is available to support family physicians in their key decisions.

In a critical analysis of the first 70 guidelines, more than 800 important diagnostic and therapeutic decision areas were found to be insufficiently supported by scientific evidence. ${ }^{29}$ This information is fed back to primary care researchers to focus their support on the greatest needs of practitioners.

The Dutch college has organized a fund for research of common disorders in family medicine. This fund, which was first available in 2002, is integrated into the research program of the national medical and health research organization, ${ }^{30}$ and its research programming is tuned to the identified priorities. In the last 2 years, 16 studies have been published on a wide variety of common subjects, such as infectious conjunctivitis, impetigo, complaints in the mouth, and therapy for emotional problems in family practice, among others. The results of these studies have been already published in Dutch and English medical journals. ${ }^{31,32}$ 
based research greatly facilitates the transfer of research findings into regular practice routines. ${ }^{33-35}$

\section{Developing Appropriate Health Policy}

The development of appropriate health policy to support community-oriented care for patients requires insight into the functioning and integration of health care services, their accessibility for all who need care, and ultimately their sustainability in communities and countries. ${ }^{36}$ Policy will be improved through a better understanding of the implications for secondary and tertiary care of preventive, diagnostic, and therapeutic interventions in family medicine. Maynard has argued that what is best (but expensive) for individuals can restrict care for others and may not be the best for populations. ${ }^{37} \mathrm{~A}$ comprehensive assessment of their community's health can help FPs choose the most effective interventions to improve individual patients' health within the prevailing circumstances. As providing anticipatory (preventive) care is an integral part of family medicine, more family medicine research should also address the benefits and risks of preventive care and health promotion-assessing the outcomes of both for a long period.$^{38}$ For instance, long-term assessment has recently cast doubts about previously celebrated protective effects of hormone replacement therapy (HRT) on heart disease ${ }^{39}$ Earlier involvement of FPs in these investigations might have exposed the harms of prolonged HRT therapy that are only now being uncovered. ${ }^{40}$

Long-term monitoring of health outcomes ${ }^{38,41}$ in the community is likely best achieved through development of sentinel practices or practice-based research networks (PBRNs) (Vignette 3). Development PBRNs in countries with underdeveloped primary care delivery systems should assist in capacity building. ${ }^{34,35,43}$ In developing countries, the promotion of very simple recording systems in networks can have a dramatic effect on detecting sources of serious illness in the community (contaminated water supply); by removing these sources, we improve the health status of the community. ${ }^{44,45}$ Simple recording systems can also powerfully inform priority setting in developing countries and encourage more efficient use of limited resources.

\section{Domain of Family Medicine Research}

Research in family medicine should be driven by questions, problems, and challenges that are derived from FPs' practices and that respect the complexity of the health problems FPs encounter. Implicit in this idea is the need to bring to family medicine research a variety of medical and behavioral disciplines. This apparent overlap with other disciplines may have contributed to confusion in defining the family medicine research domain. Family medicine research is any study that addresses questions of

\section{Vignette 3. Practice-Based Research Networks}

In an effort to support the development of practice-based research networks (PBRNs) around the world, the International Federation of Primary Care Research Networks (IFPCRN) organizes PBRNs from developed and developing countries that function in a variety of health care systems. The objective of IFPCRN is to stimulate the formation of PBRNs, to offer peer support and provide a forum to meet and exchange information, and to stimulate joint research. It meets during scientific primary care conferences (Wonca, North American Primary Care Research Group [NAPCRG]) and through e-mail. Membership is open to everyone either involved in or in the process of setting-up a PBRN. ${ }^{42}$

importance to $\mathrm{FPs}$ with the objective to improve the care of patients. It is essential to focus research on the priorities of family medicine. Effective family medicine research requires a culture in the discipline of family medicine that is more supportive of the value of research.

\section{Additional Benefits of Research}

The benefits of family medicine research also include the effects it can have on the profession. By increasing professional confidence and promoting intellectual growth and richness, the morale of the profession will be improved. A number of countries are experiencing low morale among FPs and a decline in interest of medical students to enter family medicine as a career. ${ }^{46}$ Development of research networks and programs in community practice will combat dissatisfaction and improve the intellectual stimulation for FPs overcoming concerns about the sustainability of the primary health care base in several countries ${ }^{47}$ For the discipline of family medicine, research can enhance institutional and academic status, increase the visibility of the benefits of family medicine for health care, and lead to improved professional standards. Development of family medicine research will promote standardization of terminology and diagnostic and therapeutic procedures, which in turn can enhance cooperation nationally and internationally. ${ }^{19,48-50}$

\section{Recommendation 2}

Wonca should seek the development in all its member countries of sentinel practices to provide surveillance reports on illness and diseases that have the greatest impact on patients' health and wellness in the community.

\section{Recommendation 3}

Wonca should organize a clearinghouse for the world's research expertise, training, and mentoring.

\section{Building Research Capacity}

Building research capacity and introducing a research culture are essential to realize the potential of family medicine research. The conference provided a rich 
variety of ideas, proposals, and recommendations to these ends. The discussion identified 3 general objectives for capacity building that will raise the quality of research while they make family medicine research more visible..$^{51-56}$

\section{Three General Objectives for Capacity Building}

There are 3 general objectives for research capacity building in family medicine:

1. Organizing a tight and enduring link between clinical practice and a research environment (changing the climate to supporting inquiry in the discipline)

2. Establishing an improved working relationship between family medicine researchers and the wider scientific community

3. Providing research training and a career path for family medicine researchers

Essential to research capacity building is access to a research infrastructure for researchers to meet for critical reviews of their proposals and findings, presentation of their projects, and dissemination of their results. ${ }^{57}$ An impressive number of proposals emerging from this discussion were experience-based (Vignettes 4-8). Three models integrated various aspects of capacity building and will be described in more depth: PBRNs, mentoring programs, and participatory research.

\section{Link Community-Based Physicians With \\ a Research Environment}

Developing a strong and enduring link between community-based FPs and a research environment will only occur with improvements in the interface between practice and research. Achieving this objective will require increased involvement of practicing FPs on all levels: as research leaders, participants, contributors, and users. ${ }^{10,13}$ A valuable first step is in turning passive users of research information into actively involved users. Action research or participatory research that involves communities in conducting and owning the research results is an effective method to involve FPs more directly in the research needs of their community. ${ }^{63}$ Critical appraisal of research information requires knowledge that incorporates the principles of evidence-based medicine. Direct feedback about one's own clinical performance promotes the professional use of research. Other research capacity-building strategies include the involvement of FPs on scientific panels of foundations and funding agencies, reviewing papers for (primary care) journals, and participation in audit

\section{Vignette 4. The Scottish School of Primary Care}

Capacity building for primary care research is illustrated by the Scottish School of Primary Care, founded in 2000 to build capacity for primary care research, create a culture in which research is valued and rewarded, and provide a research infrastructure to improve patient care. ${ }^{51-53}$ It directs its activities in particular at research and development in the National Health Service.

As a virtual institute, this school without walls has created a critical mass of practitioners and researchers by promoting research skills and methodological expertise, interpersonal programs, and organizational programs. It is open for everyone with a primary care research interest in Scotland and promotes interprofessional projects in particular. It coordinates funding for research collaborations (obtaining $\$ 2$ million for 4 programs) and coordinates the Scottish MSc.

It persuaded every health board in Scotland to pool their small sums of money into a single 3-year program of research worth $\$ 1.2$ million and ensured a forefront position in the current postgenomic Biobank project. Major collaborative studies undertaken are (1) an investigation into the delay between the initial symptoms of breast and bowel cancer in rural and deprived communities in 3 regions of Scotland, and (2) a randomized controlled trial of steroids and antiviral medications in Bell's palsy. The school was modeled after the Netherlands school of primary care research.

\section{Vignette 5. The Netherlands School of Primary Care Research CaRe}

The Netherlands School of Primary Care Research (CaRe) is a center of research in primary care. ${ }^{56} \mathrm{It}$ is also a virtual institute to promote medical doctor and doctoral (MD/PhD) programs for primary care (family medicine, health science, epidemiology, ethics, medical informatics, nursing). It was founded in 1995 by the universities of Maastricht, Nijmegen, and Vrije Universiteit, Amsterdam, and the Netherlands Institute of Health Care Research (NIVEL). It is recognized by the Royal Netherlands Academy of Sciences as a research center of excellence. The research program focuses on (1) promotion and health education, (2) determinants of longterm outcome of illness, (3) effectiveness of diagnostic and therapeutic interventions, and (4) quality of care, and (5) international aspects of primary care. Three practice-based research networks are linked to the research program.

The core of the school's mission is PhD training. Since 1995, more than $20 \mathrm{PhD}$ theses have been completed. The combined registrar and $\mathrm{PhD}$ training is a particular feature of training to enhance retention of research trained practitioners into clinical practice.

\section{Vignette 6. Encourage Primary Care Research and Retain Researchers}

The Brisbane Initiative pursues excellence in primary care research through international cooperation in advanced research training. ${ }^{58,59}$ The initiative comes from a number of established research groups in Europe, Australia, and North America. Specifically the initiative is directed at recruiting the most talented researchers in primary care and retaining them for a senior research career. As well as courses for advanced research skills, opportunities for exchange visits, fellowships, and research collaborations are promoted. Of particular concern is the need for primary care researchers to continue their involvement in patient care, resulting in shorter leaves than most academics demand. 


\section{Vignette 7. Estonia, Trinidad and Tobago, and the Caribbean}

Family medicine has been growing in Estonia and in Trinidad and Tobago. In Estonia after the Russian occupation ended in the early 1990s, there was a strong desire to move away from a Russian polyclinic system of primary health care delivery. Margus Lember and some other academic and physician leaders in the country developed a 750-hour curriculum to retrain the physicians from the former system into a family medicine personal care model to deliver health care. By 2000 more than 1,000 Estonian physicians completed the program and are practicing in a new model of health care delivery. There are now 2 residency training programs, so new graduates have access to training in family medicine. ${ }^{60}$

A native of Trinidad and Tobago, Rohan Mahiraj spent 2 years in Toronto obtaining a master's degree in community health (family medicine). He then returned to Trinidad and Tobago and developed a fellowship program for the University of West Indies. Thirty-five physicians who were practicing in the community have taken the program of weekly sessions distributed over 2 years and passed funding for the program will continue to allow another 2 classes of up to 20 to complete the program and that the government will make the program an integral part of the educational system. A similar program functions in Jamaica, and a small residency program has been functioning in Barbados for more than 20 years. These 3 programs plan to cooperate using distance learning courses.

\section{Vignette 8. Regional Research Development}

To encourage researchers and research development on a regional basis, the European General Practice Research Network (EGPRN) ${ }^{61}$ has since the 1970s organized a platform for aspiring family medicine researchers to meet and interact. Currently each year the network organizes stand-alone research meetings and sessions in the Wonca European regional conference. The emphasis was initially on mentoring individuals, which has resulted in a tight international network of experienced researchers. Increasingly this network also focuses on the development of a research culture in family medicine and on international research collaboration. ${ }^{57,62}$ The result has been research development on local, national, and regional levels. a rigorous examination to obtain their fellowship. It is hoped that the external

provides an excellent model for setting an initial level of funding for primary care research. ${ }^{55}$ The establishment of research funds specifically directed at research in family medicine will substantially stimulate new studies. An example is provided by the positive experience of the Dutch College of General Practitioners fund for common morbidity in family practice. ${ }^{30-32}$ The initiative based its program on established needs of family medicine for research evidence. ${ }^{27,29,64}$ (Vignette 2). Research assessment tools of the medical research council of the Netherlands are used in reviewing projects funded by this program. This model improves the relationship between family medicine researchers and the medical research establishment and builds the credibility of family medicine research. Research funders will be rewarded by improvement in the health status of their communities. The reward for universities and research institutes will also be in establishing closer links with the communities that they serve. ${ }^{64-67}$ The Australian government has committed $\$ 50$ million dollars to establishing a primary health care research infrastructure. ${ }^{67}$ This investment supports the founding of the new Australian Primary Health Care Research Institute, funds family medicine research in university departments of family medicine

projects. The role of data collectors should be regarded as a helpful first step to becoming an active participant as researcher. Equally important, though, is the role of validating the research question and methods for FPs and reviewing the implications of research findings. PBRNs and practices that consider research interests in the selection of their staff and providers should be supported.

National medical colleges, university departments of family medicine, and family medicine research institutes provide the focal points for capacity-building activities, and their establishment in every country should be promoted. These organizations and institutions can promote effective transfer of research knowledge into practice by producing guidelines, organizing conferences for practitioners and researchers, and supporting researchers with special-interest group forums, journal clubs, and family medicine research journals.

The British example of allocating a percentage of the national health care budget to research in proportion to the spending in the primary healthy care sector and rural health, finances fellowships and a scholarship program, and pays for grant-based research projects in primary care (Vignette 9).

\section{Recommendation 4}

Wonca should stimulate the development of national research institutes and university departments of family medicine with a research mission.

\section{Research Training and Career Paths}

Providing research training and career paths for FP researchers should be fostered. In most regions courses for education in basic research skills are available. To sustain benefits from the skills of those receiving research training, the tension between research development and demands from clinical work and teaching must be addressed ${ }^{54}$ Family medicine faces similar tensions between clinical and research demand to most other clinical specialties. ${ }^{68}$ Partnering in research with other specialties would foster research in all clinical domains. Universities with their departments of family medicine are in an 


\section{Vignette 9. Structuring Primary Care Research}

The Australian Primary Health Care Research Evaluation Development (PHCRED) had been structuring primary care research in a comprehensive way. The PHCRED ${ }^{67}$ strategy was developed by the Commonwealth Department of Health and Aging in consultation with General Practice Partnership Advisory Council. The strategy supports several elements that will provide support to general practice and primary health care research community. The aim is to develop both research capacity and the fields of knowledge that support the evidence base for general practice and primary health care services. The elements of the strategy include (1) a primary health care research institute, (2) a research priority-setting process, (3) a research capacity-building fund for university departments of general practice and rural health, (4) project grants in the area of primary health care, and (5) a primary health care fellowship and scholarship program for 2002 scholars. The amount of funding was $\$ 50$ million for 5 years from 2001 to 2005.

excellent position to lead the way by building partnerships with other researchers in biomedicine, health, and social sciences. ${ }^{13}$ In a number of countries, however, universities are conspicuously lacking in primary care development.

All academic FPs require protected time for research, and candidates for such positions should demonstrate that they can use this time. To achieve this goal, there is a need for research-training programs (including supported fellowships, masters' degrees, and doctorates) in family medicine research. Although there are a number of these programs in different countries, including some distance learning programs, there still needs to be an international clearinghouse so that potential researchers can easily review all available training opportunities. A number of centers of excellence ${ }^{51,56,58,59}$ can serve as a role model for other sites that might be considering similar development (Vignettes 4, 5, and 6). Promoting the benefits and domain of family medicine research should begin in undergraduate education programs, where students should be encouraged to develop their

\section{Vignette 10. Linking Family Medicine Research to Biomedical Research: The Italian Example}

Successfully linking family practice research to the biomedical research infrastructure, where no university network is available, the Centro Studie e Recerche Medicina Generale (CseRMeG) in Italy brings together family physicians to improve primary care through research and development. A feature of primary care research in Italy is the absence of university involvement. The network has established a working relation with the Institute Mario Negri-a private research institute-for methodological support and cooperation. The result has been a number of studies, of which the Primary Prevention Project on the effectiveness of low-dose aspirin and vitamin E on cardiovascular events in high-risk patients is the best known. ${ }^{65}$ This trial stands as a landmark randomized controlled trial in primary care. In addition, the network has published a textbook of family medicine. ${ }^{71}$ own research projects and to assist FP researchers on funded studies. Residency and registrar training programs should include instruction in critical appraisal of the literature, a focus on accessing and using research evidence in practice, and participating in research projects of their own. Combined residency and researchtraining programs need to be developed to prepare clinical scientists for a research career. Such programs are currently available in the Netherlands ${ }^{69}$ and Canada. ${ }^{70}$ These programs extend the length of vocational training but lead to a dual clinical and research qualification. Researchers in family medicine also need a career track and protected research time..$^{51,56}$

Independent research institutes can present a valuable alternative to universities, as illustrated by the experiences in Italy (Vignette 10). This model works by stimulating universities and institutes to extend their mission into the community and to focus on health problems that have the greatest impact on the population. ${ }^{64,65}$ The prevailing research culture is thereby changed, with an expansion of family medicine research opportunities. ${ }^{12,13}$

\section{PBRNs and Research Capacity Building}

PBRNs contribute to research capacity building by (1) collecting empirical data from family medicine, (2) connecting FPs to researchers and focusing research on important questions from practice, (3) disseminating research results in practice, and (4) stimulating research interest among FPs.

PBRNs have developed in a number of countries. $^{34,35,42,66,72-77}$ These networks are sometimes also referred to as primary care research networks. The key element of PBRNs is the bond between practice and research, and for that reason, that they are practice based is essential and therefore is used here. PBRN practices can consist of all (medical and paramedical) professionals who practice in primary care. The

\section{Vignette 11. Uncovering Common Primary Care Health Problems in Developing Countries}

In an effort to uncover the hidden burden of illness in primary care, the South African sentinel practices network (SASPAN) ${ }^{75}$ organized a network of family practices to identify and study the most common health problems. This solution addresses a major problem of primary care in developing countries by providing empirical data on the major health problems in and challenges for family practice. The network covers the most deprived areas, and its practices are faced with substantial mismatch between the demands of their practice population and the limited available resources. Among its main findings are studies of population need. Its work is currently supporting primary care by using their available resources more effectively and efficiently for patients with human immunodeficiency virus infection and acquired immunodeficiency syndrome. 
potential for research capacity building makes PBRNs a powerful generic tool, the development of which must be encouraged in every country (Vignette 3,11 ).

PBRN principles have been practiced for decades in a number of groups. In particular, in the United Kingdom and the Netherlands there is a tradition of more than 20 years of practice-directed research, resulting in high-quality data collection. ${ }^{78}$ This accomplishment is undoubtedly related to the central position of general practice in the health care system of these countries; patients are listed with the same practice and physician for decades, making the denominator of epidemiological data straightforward. These registration strategies not only help FPs build a longitudinal overview of patients' episodes of illness and medical care but also encourage research that applies this information to defined populations. Even where patients can directly access specialists without referral, examples of developing research networks and databases exist, ${ }^{34,35,72,75,77,79}$ illustrating the generic nature of PBRNs. A recent German initiative illustrates benefits from links between primary and secondary care and specific specialties. ${ }^{80}$

Analysis of empirical data directly derived from patient care is a critical step in the development of a family medicine research culture. ${ }^{76,77,79}$ The strength of PBRNs is their grounding in practice, with a strong value of ownership by participating $\mathrm{FPs}^{34,66}$ and a bottom-up approach to answering research questions that are derived from practice. Once the research questions are answered, the results can be implemented in the networks, where the practitioners have a sense of ownership of the findings. A concern about a bottom-up research network is the potential for lack of rigor and too much free-floating research. Many countries deal with this potential problem by linking PBRNs to university departments that provide supervision and methodological support for studies. ${ }^{41,66,74}$ PBRNs are also a way for universities and research institutes to broaden their research activities into the community and into primary care.

Among the most important contributions of PBRNs may be in the longitudinal collection and monitoring of morbidity data. Information about care collected during a short period is of limited relevance-and occasionally misleading. ${ }^{38}$ Longitudinal research with long-term follow-up of patients' health status can make a major contribution to better understanding of illness and disease. To achieve this goal in a PBRN, it is necessary to obtain long-term commitment from practices to continue to provide high-quality and consist data for many years. This outcome has been achieved in The Netherlands, resulting in databases that can be used as an index to recruit and select patients for research on the basis of their lifetime characteristics. ${ }^{41,74,78,81}$

\section{Recommendation 5}

Wonca should organize an expert group to provide advice for the development of PBRNs around the world.

\section{Mentoring}

Mentoring is an essential capacity-building tool in all research programs at local, national, and international levels. Formal mentoring processes include masters' degrees, medical doctor (MD), and doctoral (PhD) programs and courses. Mentors need not be based in the same institution or even, for that matter, in the same country as those they are mentoring. Mentoring by an experienced researcher of an FP interested in research in an underdeveloped country can be a powerful way to build family medicine research capacity. ${ }^{82}$ Capacity building in underdeveloped countries may also occur with external support partnerships with overseas family medicine university departments (Vignettes 7, 12, and 13). These partnerships should be on equal terms and could include student and faculty exchanges between departments.

Two mentoring approaches can be distinguished: (1) mentorship for interested individual FP researchers, and (2) mentorship between organizations, institutions and countries. There is overlap among these two approaches, and the first may lead into the second.

Two examples of mentoring individual FPs to foster research skills are (1) the 5 -weekend research programs in Canada, ${ }^{83,84}$ and (2) the activities of the European General Practice Research Network ${ }^{13,57,61,62}$ (Vignette 8). These examples stimulate FPs with a research question arising from their practice to participate in partnership with a (university-based) researcher. Mentoring can increase research knowledge and understanding in the discipline in a relatively short period.

An example of programmatic mentoring is the Bosnia-Herzegovina project (Vignette 13), to which many more experiences in eastern ${ }^{84-86}$ and southern Europe, ${ }^{87-89}$ Latin America (Vignette 12), and Africa ${ }^{90}$ can be added. By training future leaders through mentorship, optimal conditions are created to transfer research expertise from one region or country to another. Mentorship might also go beyond research to include support of education. Mentoring should be based on partnerships among universities, research institutes, and national colleges.

In the dissemination of research, conferences, journals, and Web sites play a key role. Primary care output is in danger of losing its visibility when research methods and cross-disciplinary partnerships disperse the family medicine profile of the work. The good working relationships of family medicine with many other disciplines makes loss of visibility a real danger. A Web site linkage from an international foundation family medicine Web site should be pursued. Indexing family medicine journals in a database also provides a powerful method 
to focus research output, but unfortunately the profile of family medicine journals in the most prestigious database, Index Medicus, is insufficient.

\section{Recommendation 6}

Wonca should promote research journals, conferences, and Web sites for the international dissemination of research findings and coordinate their display. A wider representation of family medicine research journals in databases like Index Medicus should be pursued

\section{Recommendation 7}

Wonca should facilitate funding of international collaborative research.

\section{Participatory Research}

In addition to PBRNs and mentoring, participatory research ${ }^{63,91,92}$ has become an established method to answer questions arising from communities. Through engaging in participatory research FPs can both use their position in the communities in which they practice and strengthen their understanding of those communities. Participatory research has in particular established its value in the introduction of (primary) health care in deprived communities by improving social and economic conditions, and effecting equity in care. Reducing distrust of an agenda of research and of care that is perceived as coming from outside - and being imposed uponthe community is the key value of participatory research and results in partnerships between family medicine researchers and the community under study. Participatory research is the process of producing new knowledge by "systematic inquiry, with the collaboration of those affected by the issue being studied, for the purposes of educa-

\section{Vignette 12. Brazil: International Partnerships and Mentoring}

In 1985 Brazil, a country with the fourth largest land mass in the world and 175 million people, moved from a military dictatorship to a democracy. Between 1987 and 1990 a new constitution was developed guaranteeing every Brazilian basic health care. In 1993 the Programe Sauda Familiale program was initiated to address the health care needs of more than two thirds of the population who had little or no access to primary health care. The federal government began building 40,000 health clinics, sharing the operating costs with municipalities. As the clinics were built, there were no physicians, nurses, or dentists with any training in primary health care. None of the 92 medical schools had a department of family medicine, and no graduates had any experience in delivery of primary health care.

A delegation from the City of Curitiba visited North America to find a university willing to provide education for the health care providers in 92 clinics the city had established by 1995 . The Department of Family and Community Medicine at the University of Toronto developed a 10-month program delivered in 5 sessions of 3 days over 1 year. The first 18 participants promised to teach the program to others after they completed the program. The program was based on the 4 principles of Canadian family medicine and also used adult education principles. After the first session, 7 teams of 2 persons each began delivering the program to colleagues. More teachers were identified in the second round. After 7 years there are more than 5,000 graduates of the program in 9 states. There are 4 residency programs in family medicine, and state and national associations have been formed. There is evidence for improving health status in the countries population. ${ }^{44}$ Interest in research in primary care has been increasing among those who have graduated from the program, with a growth in paper presentations at society meetings.

\section{Vignette 13. Bosnia-Herzegovina Family Medicine Development}

The Queen's University-Bosnia-Herzegovina Family Medicine Development Project began in 1995 when the war was still active in Sarajevo. The Queen's University School of Rehabilitation started a program in 1995 to provide community-based physical rehabilitation to war victims. The health care system was in disarray, with most medical facilities shattered and the education system in chaos. Dr Geoff Hodgetts from Queen's Department of Family Medicine, saw an opportunity to assist the Ministry of Health and Medical Faculties to rebuild medicine in a family medicine model, a major change from the Russian polyclinic system of the former Yugoslavia. During the past 7 years, 4 Bosnian medical faculties have developed departments of family medicine, overseeing 6 family medicine residency programs in more than 20 family medicine teaching centers. There are now more than 175 physicians who have graduated from the 3-year residency program, and many hundreds of nurses and other physicians have received training in primary care. The medical culture has undergone fundamental changes including the legal, political, and cultural aspects of health care. This model will be sustainable into the new future of Bosnia. Twenty-eight papers using research and evidence-based methods were presented by graduates from the program at the Wonca Europe meeting in Slovenia. This event provides evidence of the research capacity building potential of international partnerships. tion and taking action or effecting social change. ${ }^{\prime \prime 11}$ The 3 primary features of participatory research are collaboration, mutual education, and action that is relevant to the community based on the research results. Participatory research encourages partnerships between researcher and community with the goal of incorporating both researcher and community expertise throughout the research process. Participatory research also promotes community capacity building and sustainability beyond research funding. A goal is that research subjects should own the research process, develop skills, and use research results to improve their quality of life and plan for future health needs. Results of participatory research have local applicability and are transferable to other communities. ${ }^{63}$

Given the critical relation between researchers and a community (as much as with individuals under study), the potential benefits and harms for involved communities should be appraised in ethical reviews of studies. The conference identified a problem with ethical review guidelines that are insufficiently focused on the position of communities in study designs. 


\section{Recommendation 8}

Wonca should organize international ethical review guidelines in particular of participatory (action) research, where researchers work in partnership with communities. These guidelines should address the protection of the community as well as the individual.

\section{Research in Developing Countries}

Research in developing countries was reviewed extensively by the assembly, addressing the concern that developing countries had specific needs requiring extra attention. Often the capacity-building strategies that work elsewhere can be used for developing countries, and examples have been provided in the sections discussing PBRNs and mentoring. Mentorship from more developed countries provides powerful opportunities to have substantial effects from the investment of limited resources. Mentoring should be directed at the needs of the developing country rather than driven by the priorities of (commercial) mentors with insufficient ethical review.

Strategies for promoting family medicine research in developing countries should take account of the fact that FPs are often overwhelmed by clinical demands in chaotic systems. There are a number of examples where PBRNs have had a great impact on improving health in developing countries by applying simple recording methods (Vignettes 11, 12). On a larger scale, their epidemiologic analyses could dramatically improve the countries response to community needs. ${ }^{44,45,75}$ Focusing on PBRNs and mentoring the well-developed principles of community-oriented primary care in these environments have the potential to contribute to lasting and sustainable improvements in health and wellness. ${ }^{93-95}$ Even small amounts of money-for example $1 \%$ or $2 \%$ of the national budget for health-could, under these circumstances, effect enormous improvement in the health of a country's population.

\section{Recommendation 9}

In all recommendations made to support family medicine research, Wonca should address the specific needs and implications for developing countries.

\section{CONCLUSIONS AND RECOMMENDATIONS}

It was concluded that through family medicine research the effectiveness and efficiency of health care in all countries could be improved. Strengthening family medicine research is essential to enhance the role of FPs in health care systems, to improve the optimal functioning of health care systems, and to improve the health of populations.

Analysis of the conference discussion identified strengths in family medicine research from around the world and found further resources to support its devel- opment. Mentoring aspiring researchers or research organizations is increasingly driven by international organizations and provides a practical strategy for building research capacity. PBRNs are providing more information on health problems and their solutions in communities. The development of PBRNs can be supported by international collaboration.

In several European countries FPs are playing leadership roles in the biomedical research community, providing encouraging signs that FPs have broken out of their isolation from the research community. There is a need, however, to be more articulate about the achievements of family medicine research and the potential this research holds for improved medical care and improved health.

Mentoring FP researchers and PBRNs promotes a bottom-up research agenda based on evidence gaps experienced in practice. At the same time, the link of family medicine research and researchers with university departments and research institutes is important to enhance rigorous studies methods. A multidisciplinary approach is essential to combine the paradigm of illness and disease with the paradigm of whole patients and their vulnerability or resilience to illness and healthrelated behavior. ${ }^{20,96,97}$ This is the context of family medicine and the complex environment that family medicine research should be able to address.

No country can reasonably expect to improve their health care system without strong primary care. Because of their central service and leadership role in primary care, FPs worldwide must enter into research and development of their research-based discipline. If implemented, the above recommendations will substantially strengthen family medicine research around the world and enhance the care FPs render. Strengthening family medicine research will result in not a few but millions of people benefiting.

To read or post commentaries in response to this article, see it online at http:I/www.annfammed.org/cgi/content/full/2/suppl_2/S5.

Key words: Family practice; general practice; research development; capacity building, world health

A version of this paper was presented at the Wonca Research Conference, Kingston, Ontario, Canada, March 8-11, 2003.

\section{References}

1. Institute of Medicine. Committee on Quality of Health Care in America. Crossing the Quality Chasm. A New Health System for the 21st Century. Washington, DC: National Academies Press; 2001.

2. Starfield B. Is primary care essential? Lancet. 1994; 344:129-133.

3. Green LA, Fryer, GE, Yawn, BP, Lanier D, Dovey, SM. The ecology of medical care revisited. N Engl J Med. 2001; 344:2021-2025.

4. van Weel, C. International research and the discipline of family medicine. Eur J Gen Pract. 1999; 5:110-115. 
5. Wonca Europe. The European definition of general practice/family medicine. Wonca Europe 2002. Available at: http://www.globalfamily doctor.com/publications/Euro_Def.pdf. Accessed March 10, 2004.

6. Donaldson M, Yordy K, Vanselow N, eds. Defining Primary Care: An Interim Report. Washington, DC: Institute of Medicine; 1994.

7. Rosser WWW, Dovey S, Green LA, Phillips R, Fryer E. The evolving role of the family physician in Canada. Can Med Association J (Submitted).

8. De Maeseneer JM, De Sutter A. Why research in family medicine? Ann Fam Med. 2004;2:(Suppl 2):S17-S22.

9. Green LA. The research domain of family medicine. Ann Fam Med. 2004;2(Suppl 2):S23-S29

10. Del Mar C, Askew D. Building family medicine research capacity. Ann Fam Med. 2004;2(Suppl 2):S35-S40.

11. Hutchinson A, Becker L. Styles and methods of family medicine: their impact on the research agenda. Ann Fam Med. 2004;2(Suppl 2): S41-544.

12. Lam CLK. The 21st century: the age of family medicine research? Ann Fam Med. 2004;2(Suppl 2):S50-S54.

13. Svab I. Changing research culture. Ann Fam Med. 2004;2(Suppl 2): S30-S34.

14. Bentzen N. Family medicine research: implications for Wonca. Ann Fam Med. 2004;2(Suppl 2):S45-S49.

15. Sparks B., Gupta S. Research in family medicine in developing countries. Ann Fam Med. 2004;2(Suppl 2):S55-S59.

16. Herbert CP. Future of research in family medicine: where to from here? Ann Fam Med. 2004;2(Suppl 2):S60-S64.

17. Anonymous. Is primary-care research a lost cause? Lancet. 2003; 361:977.

18. Starfield B. Primary Care: Balancing Health Needs, Services And Technology. New York, NY: Oxford University Press; 1998.

19. Wonca International Classification Committee. International Classification of Primary Care, ICPC-2. 2nd ed. Oxford: Oxford Press, 1998.

20. McWhinney IR. A Textbook of Family Medicine. 2nd ed. New York, NY: Oxford University Press; 1997.

21. Rosser WWW, Shafir MS. Evidence-Based Family Medicine. Hamilton, Decker Inc. 1998.

22. De Melker RA. Diseases: the more common the less studied. Fam Pract. 1995;12:84-87.

23. Rosser WW. Applying evidence from randomized controlled trials in general practice. Lancet. 1999;353: 661-663.

24. Okkes IM, Oskam SK, Lamberts H. The probability of specific diagnoses for patients presenting with common symptoms to Dutch family physicians. J Fam Pract. 2002;51:31-36.

25. van Weel C. Examination of context of medicine. Lancet. 2001;357: 733-734.

26. Cochrane collaboration Web site. Available at: http://www.cochrane. org. Accessed March 10, 2004.

27. Dutch College of Family Physicians. Available at: http://nhg.artsennet.nl/ content/resources/AMGATE_6059_104_TICH_L748610903/AMGATE_ 6059_104_TICH_R119952487066081 Accessed March 9, 2004.

28. Guideline Advisory Committee of the Ontario Medical Association/ Ministry of Health and Long Term Care of Ontario Web site. Available at: http://www.gacguidelines.ca/. Accessed March 9, 2004.

29. Dutch College of General Practitioners (NHG) Overview of underresearched areas in family medicine. Available at: http://nhg.artsennet.nl/ content/resources/AMGATE_6059_104_TICH_L866838437/AMGATE 6059_104_TICH_R1196231005919511 also: Tasche M, Oosterberg E, Kolnaar B, Rosmalen K. Inventarisatie van lacunes in huisartsgeneeskundige kennis. HuisartsWet. 2001;44:91-95. Accessed March 9, 2004.

30. ZonMW research fund 'common morbidity in general practice'. Available at: http://zonmw.collexis.net/default.asp?key= prog. Accessed March 10, 2004.
31. Deconnick S, Boeke AJP, van der Waal I, et al. Incidence and management of oral conditions in general practice. $\mathrm{Br} J$ Gen Pract. 2003;53:130-133

32. Koning S, van Suijlekom LWA, Nouwen JL, et al. Fusidic acid cream in the treatment of impetigo in general practice: double blind randomised placebo controlled trial. Br Med J. 2002;324:203-206.

33. van Weel C, Gouma DJ, Lamberts SWJ. De bijdrage van klinisch wetenschappelijk onderzoek aan een betere patientenzorg [English abstract]. Ned Tijdschr Geneesk. 2003:147:229-233.

34. Nutting PA, Beasley JW, Werner JJ. Asking and answering questions in practice: practice based research networks build the science base of family practice. JAMA. 1999; 281:686-688.

35. Green LA, Dovey SM. Practice-based primary care research networks. They work and are ready for full development and support. BMJ. 2001;322:567-568.

36. Nutting PA, ed. Community-Oriented Primary Care: From Principle to Practice. Washington, DC: US Department of Health and Human Service; 1987.

37. Maynard A. Evidence-based medicine: an incomplete method for informing treatment choices. Lancet. 1997;349:126-128.

38. Pincus T. Analyzing long-term outcomes of clinical care without randomized comtrolled clinical trials: the consecutive patient questionnaire database. J Mind-Body Health. 1997;13:3-32.

39. Writing Group for the Women's Health Initiative Investigators. Risks and benefits of estrogen plus progesterone in healthy postmenopausal women: principle results from the Women's Health Initiative randomized trial. JAMA. 2002;288:321-333.

40. Lagro-Janssen ALM, Rosser WWW, van Weel C. Breast cancer and hormone replacement Therapy: up to general practice to collect the pieces. Lancet. 2003;362:414-415.

41. de Grauw W, van de Lisdonk EH, van den Hoogen HJM, van Weel C. Cardiovascular morbidity and mortality of type 2 diabetes patients. Diabetic Med. 1995;12:117-122.

42. International Federation of Primary Care Research Networks. Available at: http://groups.msn.com/IFPCRN. Accessed March 09, 2004.

43. Lionis C, Trell E. Health needs assessment in general practice: the Cetan approach. Eur J Gen Pract. 1999;5:75-77.

44. Sant'Ana AM, Rosser W, Talbot Y. Five years of health care in Sao Jose. Fam Pract. 2002;19:410-415.

45. Isaakidis $P$, Swingler GH, Piennaar EE, Volmink NJ, loannina JPA. Relations between burden of disease and randomized evidence in sub-Sahara Africa: survey of research. Br Med J. 202;324:702-705.

46. Del Mar CB, Freeman GK, van Weel C. Only a GP: is the solution to the general practice crisis intellectual? Med J Aust. 2003;179: 26-29.

47. Rosser W. The decline of family medicine as a career choice. CMAJ. 2002;166:1419-1420.

48. Okkes, IM, Jamoulle, M., Lamberts, H., Bentzen, N. ICPC-2-E, the electronic version of ICPC-2. Differences with the printed version and the consequences. Fam Pract. 2000;17:101-106.

49. Bentzen $N$, ed. An international glossary for general practice/family medicine. Fam Pract. 1995;12: 341-369.

50. Bentzen N, ed. Wonca Dictionary of General/Family Practice. Copenhagen: Maanedsskrift for Praktisk Laegegering, 2003. Available at: http: I/www.globalfamilydoctor.com. Accessed March 11, 2004.

51. Scottish School of Primary Care. Available at: http://www.sspc.uk.com. Accessed March 09, 2004.

52. Sullivan FM, Lewison G, Clarkson J. What Scottish primary care researchers are doing to recover their standing in the UK. Health Bull (Edinb). 2002;60:1-4.

53. Wyke S, Bond C, Morrison J, Ryan K, Sullivan F, for the Office Primary Care Implementation Committee. Research priorities in primary care. A report from the CSO's primary care implementation committee. Health Bull (Edinb). 2000 58:426-433. 
54. North American Primary Care Research Group Committee on Building Research Capacity and the American Family Medicine Organizations Research Subcommittee. What does it mean to build research capacity? Fam Med 2002;34:678-684.

55. Mant D. Research and Development in Primary Care. National Working Group Report. Bristol, NHS Executive South and West; 1997.

56. The Netherlands School of Primary Care Research (CaRe). Available at: http://www.researchschoolcare.nl. Accessed March 9, 2004.

57. Lionis C, Stoffers HEJH, Hummers-Pradier E, Griffiths F, Rotar-Pavlic D, Rethans JJ. Setting priorities and identifying barriers for general practice research in Europe. Results from an EGPRN meeting. EGPRN report 2003. Email address EGPRN: hanny.prick@hag.unimaas.nl. Accessed March 10, 2004

58. van Weel C. The Brisbane Initiative: International Advanced Education for Primary Care Research. The Brisbane Initiative: pursuing advanced research training and the establishment of a future research leadership for primary care. 2003. Available at: http://www.globalfa milydoctor.com .Accessed March 09, 2004.

59. Kochen MM. Excellence in primary care research: which requirements are needed? Eur J Gen Pract. 2003;9:39-40.

60. Kalda R, Maaroos HI, Lember M. Motivation and satisfaction among Estonian family doctors working in different settings. Eur J Gen Pract. 2000;6:9-15.

61. The European General Practitioners Research Network (EGPRN). Available at: http://www.egprw.org. Accessed March 09, 2004.

62. Royen P van, Griffith F, Lionis C, Rethans JJ, Sandholzer H, Gali F. A research strategy for EGPRW. Eur J Gen Pract. 2000;6:69-71.

63. Mccauly AC, Gibson N, Freeman W, et al. Participatory research maximises community and lay involvement. Br Med J. 1999;319:774-778.

64. Interfaculty Council of Departments of General Practice: Report results academic practices network 1992-1997 (Interfacing Overleg Huisartsgeneeskunde: Rapportage Academisch Werkveld Huisartsgeneeskunde 1992-1997). Nijmegen: Department of General Practice, University of Nijmegen, 1998.

65. Collaborative group of the Primary Prevention Project (PPP). Lowdose aspirin and vitamin $\mathrm{E}$ in people at cardiovascular risk. Lancet. 2001;357:89-95.

66. van Weel C, Smith H, Beasley JW. Family practice research networks Experience from three countries. J Fam Pract. 2000;49:938-943.

67. Australian Gouvernment Department of Health and Ageing's Primary Health Care Research, Evaluation Development Strategy. Available at: http://www.phcris.org.au/resources/phcred/PHC_RED_ frameset.html. Accessed March 09, 2004.

68. Anonymous. Researcher, clinician or teacher? Lancet. 2001;357: 1543.

69. The Netherlands Organisation of Scientific Research and Zon/MW, programme 'Clinician-researcher'. Available at http://www.zonmw.nl/ index.asp? $\mathrm{a}=32111 \mathrm{gs}=3789 \varepsilon p=1$. Accessed March 11, 2004.

70. Queens University FP/MSc researcher residency program. Queens University Department of Family Medicine, Kingston, Ontario, Canada. July 2003. Available at: http://www.queensu.ca/fmed/ resprojects.htm. Accessed March 09, 2004

71. Caimi V, Tombesi M, eds. Medicina Generale. Turin, Unione Tipografico-Editrice Torinese; 2003.

72. Gunn J. Should Australia develop primary care research networks? Med J Aust. 2002;177:63-66.

73. Smith HD, Dunleavey J. Wessex primary care research network: a report on two years progress. Southampton Health Journal. 1996;3: 43-47.

74. Metsemakers JF, Hoppener P, Knottnerus JA, Kocken RJ, Limonard CB Computerized health information in The Netherlands: a registration network of family practices. Br J Gen Pract. 1992;42:102-6. Registratie Netwerk Huisartsen (RNH) Available at: http://www.hag.unimaas.nl/ RNH. Accessed March 09, 2004).
75. Pather MK. SASPREN - South African Sentinel Practitioner Research Network Family Practitioner Primary Health Care Surveillance Project. Report for 2000/2001. Stellenbosch Department of Family Medicine and Primary Care: University of Stellenbosch; 2002.

76. Culpepper L, Froom J. The International Primary Care network: purpose, methods and policies. Fam Med. 1988;20:197-201.

77. Green LA, Wood M, Becker L, et al. The Ambulatory sentinel Practice Network: purpose, methods and policies. J Fam Pract. 1984;18:275-280.

78. van Weel, C. Validating long term morbidity recording. J Epidemiol Commun Health. 1995;49(Suppl 1):29-32.

79. De Maeseneer JM. Huisartsgeneeskunde: een Verkenning [dissertation, English summary]. Belgium: University of Ghent; 1989.

80. Bundesministerium für Bildung und Forschung, networks of competence. Available at: http://www.kompetenznetze.de/ index.php?sprache =2. Accessed March 10, 2004.

81. Lamberts H, Brouwer HJ, Mohrs J. Reason for Encounter, Episode and Process-oriented Standard Output From the Transition Project. Amsterdam Department of General Practice/Family Medicine: University of Amsterdam; 1991.

82. Costello A, Zumla A. Moving to research partnerships in developing countries. BMJ. 2000;321:827-829.

83. Talbot Y, Batty H, Rosser W. Five weekend national family medicine fellowship: program for faculty development. Can Fam Phys. 1997;43: 2151-2157.

84. Department of Family Medicine, Queens University Kingston Ontario IOntario College of Family Physicians. Five weekend research program: Available at: http://www.queensu.ca/fmed/CSPC-OCFP.htm. Accessed March 12, 2004.

85. Evans PR. Medicine in Europe: the changing scene in general practice in Europe. Br Med J 1994:308:645-648.

86. Svab I, Yaphe Y, Correia de Sousa J, Passerine G. An international course for faculty development in family medicine: the Slovenian model. Med Educ. 1999;33: 80-81.

87. Kounalakis D, Lionis C, Okkes I, Lamberts H. Developing an appropriate EPR system for the Greek primary care setting. J Med Sys. 2003;27:239-246

88. Koutis A, Isacsson A, Lionis C, Lindholm L, Svenninger K, Fioretos $M$. Differences in the diagnosis panorama in primary health care in Dalby, Sweden and Spili, Crete. Scand J Soc Med. 1993;21:51-58.

89. Lionis C, Koutis A, Antonakis N, Isacsson A, Lindhol L, Fioretos M. Mortality rates in a cardiovascular 'low risk' population in rural Crete. Fam Pract. 1993;10:300-304.

90. De Maeseneer J. Optimisation of the vocational training in family medicine in South-Africa: a contribution to the realisation of health for all [Vlir - Own Initiatives. El - SEL2003-14]. Ghent, Department of Family Medicine and Primary Health Care, 2003. Available at: http://allserv.rug.ac.be/ apeleman/huisartsgeneeskunde Folder/ huisartsgeneeskunde/NewFiles/hoofdmenu/hoofdmenu.htm. Accessed March 09, 2004.

91. Green LW, George MA, Daniel M, et al. Study of Participatory Research in Health Promotion. Ottawa: Royal Society of Canada; 1994.

92. Phillips WR, Grams GD. Involving patients in a primary care research meeting worked well. BMJ. 2003; 326:1329.

93. Iliffe $S$, Lenihan $P$, Wallace $P$, Drennan V, Blanchard M, Harris A. Applying community-oriented primary care methods in British general practice: a case study. Br J Gen Pract. 2002;52:646-651.

94. Nutting PA, Wood M, Conner EM. Community oriented primary care in the United States. A status report. JAMA. 1985;253:1763-1766.

95. Kark SL, Kark E. An alternative strategy in community health care: community-oriented primary health care. Isr J Med Sci. 1983;19:707-713.

96. McWhinney IR. Being a general practitioner: what it means. Eur J Gen Pract. 2000;6:135-139.

97. Huygen FJA. Family Medicine: The Medical Life History Of Families. New York, NY: Brunner Maze; 1982. 